\title{
Effect of combining cellulose nanocrystals and graphene nanoplatelets on the properties of poly(lactic acid) based films
}

\author{
S. Montes ${ }^{1 *}$, A. Etxeberria ${ }^{2}$, V. Mocholi ${ }^{3}$, A. Rekondo $^{1}$, H. Grande ${ }^{1,2}$, J. Labidi $^{4}$ \\ ${ }^{1}$ CIDETEC, Parque Científico y Tecnológico de Gipuzkoa, Paseo de Miramón, 196, 20014 Donostia-San Sebastian, Spain \\ ${ }^{2}$ POLYMAT, Polymer Science and Technology Department, Faculty of Chemistry, University of the Basque Country \\ (UPV/EHU), 20018 Donostia-San Sebastian, Spain. \\ ${ }^{3}$ AIMPLAS, Área de Envases - Laboratorio Químico. Calle Gustave Eiffel, 4. 46980 Paterna.Valencia, Spain. \\ ${ }^{4}$ Chemical and Environmental Engineering Department, University of the Basque Country, Plaza Europa 1, \\ 20018 Donostia-San Sebastian, Spain
}

Received 16 November 2017; accepted in revised form 22 January 2018

\begin{abstract}
In the present work, cellulose nanocrystals (CNC) and graphene nanoplatelets (GR) were combined in two different ratios and incorporated into polylactic acid (PLA) by melt blending technique, at a total loading level of $1 \mathrm{wt} \%$. The obtained PLA-CNC/GR nanocomposites were further processed by hot pressing for manufacturing films. For comparison purposes, PLA-CNC, PLA-GR and PLA-T (PLA blended with the organic surfactant Triton X-100) compositions were also prepared following the same procedure.

The produced materials were characterized by several techniques, including Field-Emission Scanning Electron Microscopy (FE-SEM). The mechanical properties assessment showed an increase of 8 and $11 \%$ in the Young's modulus and tensile strength respectively for PLA- CNC/GR (ratio 50/50) film compared to PLA-T. The thermal properties were also positively influenced by the incorporation of both nanofillers. Similarly, the gas barrier properties were improved by $23 \%$ in Oxygen Transmission Rate (OTR) for films containing simultaneously CNC and GR. Finally, the antifungal properties were evaluated against Aspergillus Niger finding a superior antifungal activity in the CNC/GR hybrid films. The incorporation of CNC and GR in PLA showed a favourable impact in the overall properties of the obtained materials with only $1 \mathrm{wt} \%$ of nanofiller content. These results suggest that CNC/GR hybrid nanocomposites have a considerable potential in agricultural films or in food packaging trays applications.
\end{abstract}

Keywords: biopolymers, biocomposites, nanocomposite, graphene, cellulose nanocrystals

\section{Introduction}

In the last few decades the Bioplastics market, including bio-based and biodegradable plastics [1,2], has increased considerably with a growing rate by about 20 to 100 per cent per year according to the European Bioplastic association. Known petroleum reserves depletion, plastic disposal problems in landfills and incineration emissions, together with more restrictive environmental regulations, has increased the interest in the development of environmentally friendly plastic materials. Research efforts have shifted towards the development of biomass-based plastics, independent of fossil fuels [3].

Polylactic acid (PLA), a biodegradable aliphatic polyester derived from lactic acid, can be produced from renewable sources [4]. PLA is a real alternative for fossil-based polymers in many applications, since it is widely available at industrial scale [5] and presents good performance in terms of mechanical properties (high strength and high Young's modulus), biocompatibility and biodegradability. These properties make it suitable for biodegradable and biocompatible 
artificial scaffolds and drug delivery carriers [6-8]. However, its brittleness, low crystallization rate and low melt strength are some of the limitations of this material to be used for example in agricultural applications compared with currently used plastics, such as polyethylene [9]. Likewise, other properties such as its gas barrier properties, restrict the complete access of this biopolymer to high-volume industrial sectors like packaging [10].

Common strategies used to overcome the intrinsic drawbacks of PLA include the addition of plasticizers, copolymerization and blending with toughening polymers and the preparation of bio- and nanocomposites [11-13].

With the aim of creating fully bio-based materials, in the last decade, research has been focused on the use of cellulosic reinforcing fillers $[14,15]$. In this regard, cellulose nanocrystals (CNC), the result of submitting cellulose microfibrils to a strong acid hydrolysis treatment, have been extensively investigated in the preparation of polymer biocomposites, due to their reinforcing capability, abundance, low weight and biodegradability [16].

On the other hand, graphene (GR), the elementary structure of graphite, possesses excellent thermal, mechanical and electrical properties and high surface area. This attractive nanomaterial has been successfully used in the preparation of PLA nanocomposites for improving mechanical, thermal and barrier properties with relatively low nanofiller content (below $1 \mathrm{wt} \%)$ [17-20].

The combination of different nanomaterials has also been investigated for the preparation of multifunctional materials. $\mathrm{CNC}$ and silver nanoparticles have been combined for improving gas barrier properties and the anti-microbial activity in PLA bionanocomposites with excellent results [21-23]; while the combination of expanded graphite/layered silicate clay has led to the improvement of the thermal and fire retardant properties of PLA [24].

In a previous work, the authors studied the effect of incorporating cellulose nanocrystal-stabilized graphene (GR-CNC) produced by liquid phase exfoliation into poly(vinyl alcohol) [25]. The resulting film exhibited superior mechanical and thermal properties than films reinforced with only CNC or GR, suggesting a synergistic reinforcing effect due to the combination of $\mathrm{CNC}$ and GR. This significant reinforcement effect found was attributed to the strong interaction between the matrix and both nanomaterials.
In this study, CNC and GR reinforced PLA nanocomposites were prepared by melt mixing technique, followed by hot pressing for films manufacturing. The effect of combining both nanomaterials at a low loading level $(1 \mathrm{wt} \%)$ on the mechanical, thermal, gas barrier and antifungal properties of the films were investigated. The $\mathrm{CNC/GR}$ ratios were selected on the bases of previous studies with PVA [25], in which the best results were obtained for 95/5 ratio. Interestingly, the resulting films showed an improvement on the studied properties in comparison with the reference PLA.

\section{Experimental part}

\subsection{Materials}

Triton X-100 was purchased from Panreac (Barcelona, Spain) and Poly(lactic acid) (Futerro L-PLA, Molecular weight $180000 \mathrm{~g} \cdot \mathrm{mol}^{-1}$ ) was obtained from Futerro, (Escanaffles, Belgium). Graphene nanoplatelets (GNP, grade 3 industrial grade), were purchased from Cheap Tubes Inc. (Cambridgeport, USA) with the following characteristics: $97 \%$ of purity, average thickness of $8 \mathrm{~nm}$, maximum length $2 \mu \mathrm{m}$, and surface area between 600 and $700 \mathrm{~m}^{2} \cdot \mathrm{g}^{-1}$. Microcrystalline cellulose (MCC) was purchased from SigmaAldrich (Saint Louis, MO, USA). Sulfuric acid $\left(\mathrm{H}_{2} \mathrm{SO}_{4}, 98 \%\right)$ and sodium hydroxide $(\mathrm{NaOH})$ were purchased from Scharlau (Barcelona, Spain).

\subsection{Preparation of cellulose nanocrystals}

$\mathrm{CNC}$ were extracted from $\mathrm{MCC}$ by acidic hydrolysis with sulfuric acid. Briefly, MCC powder (20 g) was added to a preheated solution of $64 \% \mathrm{w} / \mathrm{w}$ sulfuric acid $(175 \mathrm{~mL})$ and reacted with vigorous stirring at $45^{\circ} \mathrm{C}$ for $45 \mathrm{~min}$. The reaction was quenched with $5 \mathrm{~L}$ of deionized water and allowed to settle overnight. Then, the suspension was centrifuged at $3500 \mathrm{rpm}$ for $30 \mathrm{~min}$. The precipitate was repeatedly rinsed and centrifuged with deionized water until the supernatant became turbid. Further CNC purification was done by dialysis against deionized water until reaching a pH 5-6 (membrane Spectra/Por 2, MWCO 12000-14000).

In order to facilitate the dispersion in the PLA matrix, CNC surface was modified by adding Triton X100, a nonionic surfactant (octylphenol ethoxylate) in a $1 / 4(\mathrm{w} / \mathrm{w})$ ratio following a similar protocol than those reported by Fortunati et al. [23]. To improve the thermal stability of CNC during processing steps, the $\mathrm{pH}$ of $\mathrm{CNC}$ suspension was raised to approximative- 
ly 9 by adding $1 \% \mathrm{w} / \mathrm{w}$ of $0.25 \mathrm{~mol} / \mathrm{L} \mathrm{NaOH} \mathrm{[22].}$ Finally, the nanocrystals were freeze-dried and stored until use.

\subsection{Preparation of PLA-based films}

PLA nanocomposites were prepared by melt compounding of $1 \mathrm{wt} \%$ of nanofillers with PLA using an internal mixer (Haake PolyLab QC, Karlsruhe, Germany) at a mixing temperature of $185^{\circ} \mathrm{C}$, chosen on the basis of the crystalline melting analysis of differential scanning calorimetry. The mixing was performed for 10 minutes at $70 \mathrm{rpm}$ with a batch size of $50 \mathrm{~g}$ to ensure that the different compounds went through similar shear exposure and thermal history.

CNC and GR nanofillers were used for the preparation of a series of PLA nanocomposites, as it is shown in Table 1. PLA-CNC/GR nanocomposites were prepared using two different CNC/GR ratios, 50/50 and 95/5 while keeping the total loading level at $1 \mathrm{wt} \%$. In order to facilitate the incorporation of GR in the compound it was previously dispersed in Triton X100 surfactant, which is present in all the compositions. For comparison purposes, nanocomposites containing $1 \mathrm{wt} \% \mathrm{CNC}$ and $1 \mathrm{wt} \%$ GR were also prepared. Moreover, a reference sample, named PLA-T, with $4 \mathrm{wt} \%$ of Triton X-100 ( $4 \mathrm{wt} \%$ was the overall content of Triton X-100 in all the nanocomposite formulations) was prepared following the same procedure. These formulations were further used for the manufacturing of films by hot pressing. For that purpose, $20 \mathrm{~g}$ of each formulation were placed into plates of $90 \times 90 \mathrm{~mm}$ and a $0.3 \mathrm{~mm}$ thickness using a Vogt hot plates press (LABO PRESS 200T, Technik Vogt $\mathrm{GmbH}$, Möhnesee, Germany) at $185^{\circ} \mathrm{C}$. Samples were pressed in three steps of 5 minutes each at 100, 200 and 300 bars to ensure the removal of air bubbles.

\subsection{Characterization}

\subsubsection{Morphological characterization}

The CNC surface morphology and the cross sections of the nanocomposites were analyzed using a ULTRA

Table 1. Composition of PLA-based formulations.

\begin{tabular}{|l|c|c|c|c|}
\hline \multicolumn{1}{|c|}{ Sample } & $\begin{array}{c}\text { PLA } \\
{[\mathbf{w t} \%]}\end{array}$ & $\begin{array}{c}\text { CNC } \\
{[\mathbf{w t} \%]}\end{array}$ & $\begin{array}{c}\text { GR } \\
{[\mathbf{w t} \%]}\end{array}$ & $\begin{array}{c}\text { Triton X-100 } \\
{[\mathbf{w t} \%]}\end{array}$ \\
\hline PLA-T & 96 & - & - & 4 \\
\hline PLA-CNC & 95 & 1.00 & - & 4 \\
\hline PLA-CNC95/GR5 & 95 & 0.95 & 0.05 & 4 \\
\hline PLA-CNC50/GR50 & 95 & 0.50 & 0.50 & 4 \\
\hline PLA-GR & 95 & - & 1.00 & 4 \\
\hline
\end{tabular}

plus ZEISS field emission scanning electron microscope (FE-SEM, Oberkochen, Germany).

\subsubsection{Structural characterization}

The X-ray diffraction patterns of $\mathrm{CNC}$ and MCC were recorded by using a Bruker AXS-D8 Advance $\mathrm{X}$-ray diffractometer (XRD, Karlsruhe, Germany) with $\mathrm{Cu} \mathrm{Ka}$ radiation. The measurements were carried out between $2 \theta$ values from 5 to $40^{\circ}$.

\subsubsection{Thermal properties}

Differential scanning calorimeter (DSC, Pyris Diamond DSC Perkin Elmer, Waltham, Massachusetts, U.S.A.) measurements were performed in the temperature range from 25 to $210^{\circ} \mathrm{C}$, at a scan rate of $10^{\circ} \mathrm{C} \cdot \mathrm{min}^{-1}$, performing two heating and one cooling scans. Melting temperature $\left(T_{\mathrm{m}}\right)$, cold crystallization temperature $\left(T_{\mathrm{CC}}\right)$, melting enthalpy $\left(\Delta H_{\mathrm{m}}\right)$ and cold crystallization enthalpy $\left(\Delta H_{\mathrm{CC}}\right)$, glass transition temperature $\left(T_{\mathrm{g}}\right)$ were determined from the first heating scan. The crystallinity degree was calculated using Equation (1):

$\chi[\%]=\frac{\Delta H_{\mathrm{m}}}{\Delta H_{0}} \cdot \frac{100}{w}$

where $\Delta H_{\mathrm{m}}$ is the enthalpy for melting, $\Delta H_{0}$ is enthalpy of melting for a $100 \%$ crystalline PLA sample, taken as $93 \mathrm{~J} / \mathrm{g}$ [26] and $w$ is the weight fraction of PLA in the sample. The enthalpy for melting includes the enthalpies of cold crystallization and premelt crystallizations already subtracted [15].

The thermal stability of PLA based systems was investigated by thermogravimetric analysis (TGA) and performed on a TGA Q500 (TA instruments, New Castle, DE, USA) at a heating rate of $10^{\circ} \mathrm{C} \mathrm{min}^{-1}$ in a nitrogen atmosphere until $600^{\circ} \mathrm{C}$.

\subsubsection{Mechanical properties}

The mechanical properties of reference PLA and PLA-based nanocomposites were evaluated by tensile tests (ISO 527-3) using a universal testing machine model 3365 (Instron, Norwood, MA, USA). Rectangular test specimens $(65 \mathrm{~mm} \times 12 \mathrm{~mm})$ with a crosshead speed of $5 \mathrm{~mm} \cdot \mathrm{min}^{-1}$, and an initial gauge length of $25.4 \mathrm{~mm}$ were used. Average tensile strength $\left(\sigma_{\mathrm{b}}\right)$, elongation at break $\left(\varepsilon_{\mathrm{b}}\right)$ and elastic modulus $(E)$ were calculated from the resulting stressstrain curves. The measurements were done at room temperature and at least eight samples were tested. 


\subsubsection{Gas barrier properties}

Oxygen permeability

Oxygen transmission rate (OTR) was measured with an oxygen permeation analyzer, OXTRAN 2/21 MOCON (Minneapolis, USA), according to ASTM F1927-14. Films with an OXTRAN MOCON specific shape were employed for each formulation. Films thicknesses were measured with a MAHR Digital Micrometer to $\pm 0.001 \mathrm{~mm}$. Samples were clamped in the diffusion chamber at $23 \pm 2{ }^{\circ} \mathrm{C}, 1 \mathrm{~atm}$ and at $50 \%$ relative humidity, $R H$. Pure oxygen $(99.9 \%)$ was humidified first at desired RH and then introduced into the inner half of the sample chamber while nitrogen was injected into the outer half where an oxygen sensor was placed. At least two samples for each formulation were tested in order to have statistical data. The equipment gives directly the oxygen transmission rate, which multiplied by the film thickness $(l)$, has been changed to more usual permeability coefficient in Barrer according to Equation (2):

OTR $\left[\frac{\mathrm{cm}^{3}}{\mathrm{~m}^{2} \cdot \mathrm{s}}\right] \cdot l[\mathrm{mil}]=\frac{0.038617}{p[\mathrm{~cm} \cdot \mathrm{Hg}]}=P$ [Barrer $]$

\section{Water vapour permeability}

Water vapour transmission rate ( $W V T R)$ was determined at $25^{\circ} \mathrm{C}$ according to ASTM E96-95 standard employing a permeation gravimetric cell made of polytetrafluoroethylene. The cell is a small container partially filled with water and a polymer membrane sealing it. Experiments were carried out in a Sartorius $\mathrm{BP} 210 \mathrm{D}$ balance with $10^{-5} \mathrm{~g}$ readability and the weight loss was recorded in a computer for data treatment. $W V T R$ values were calculated from the Equation (3):

$$
\text { WVTR }\left[\frac{\mathrm{g} \cdot \mathrm{mm}}{\mathrm{m}^{2} \cdot \text { day }}\right]=8,64 \cdot 10^{-5} \frac{s \cdot l}{A\left(a_{\mathrm{int}}-a_{\mathrm{out}}\right)}
$$

where $s$ is the slope of the plot of permeated mass versus time, $l$ is the thickness of the membrane $[\mu \mathrm{m}]$, $A$ is the area of the film $\left(2.54 \mathrm{~cm}^{2}\right), a_{\text {int }}$ and $a_{\text {out }}$ are the water vapour activity inside and outside the permeation cell. The permeability data shown are the average of at least 3 measurements.

\subsubsection{Antifungal activity of films}

Antifungal activity of films was evaluated with the mould Aspergillus Niger Tiegh (MB284309) (CBSKNAW, Holland) to determine the influence of
CNC/GR nanofillers introduced into the PLA matrix. A. Niger was previously cultured in solid substrate of malt extract agar (MEA, Sharlau) and incubated in sealed Petri dishes for $72 \mathrm{~h}$ at $25 \pm 1.5^{\circ} \mathrm{C}$ within a Selecta Medilow climatic chamber. After growing, an aliquot of spores was diluted in Ringer solution and aseptically inoculated on the surface containing film by using a spray ( $40 \mu \mathrm{L}$ of dissolution at $1.05 \cdot 106$ Spores $\mathrm{mL}^{-1}$ ). After 7 days of incubation at $25 \pm 1.5^{\circ} \mathrm{C}$, films were gently extracted from the agar and washed with Ringer solution. The obtained spore solution was vortexed and stained with LPCB to count spores concentration and using trypan blue solution for viability analysis. The cell concentration was determined with a Cellometer ${ }^{\circledR}$ Mini (Nexcelom Bioscience LLC, Massachusetts, U.S.A.) automated cell counter by putting $20 \mu \mathrm{L}$ of each spore solution inside Cellometer ${ }^{\circledR}$ Counting Chamber and using Cellometer ${ }^{\circledR}$ Mini software for the analysis. The values obtained for the concentration of each sample correspond to the average of three independent experiments. The fungal growth inhibition $(F G I)$ was calculated as concentration of spores (conidia) per milliliter, according to the Equation (4):

$F G I[\%]=\frac{C_{\mathrm{g}}-F_{\mathrm{g}}}{C_{\mathrm{g}}} \cdot 100$

where $C_{\mathrm{g}}$ is the average concentration in the control set (A. Niger only) and $F_{\mathrm{g}}$ is the average concentration in the different film set.

\section{Results and discussion}

\subsection{Cellulose nanocrystals characterization}

$\mathrm{CNC}$ produced by acidic hydrolysis process were morphologically characterized by FE-SEM. Figure 1

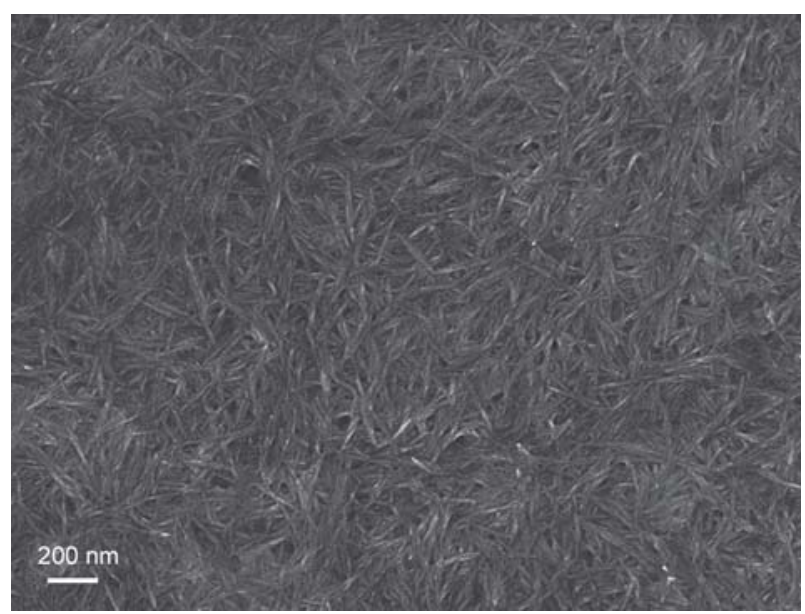

Figure 1. FE-SEM micrograph of freeze-dried cellulose nanocrystals. 


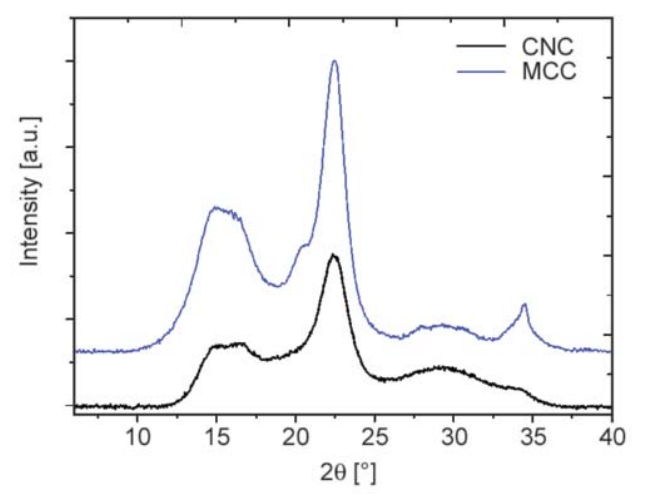

Figure 2. X-ray diffraction patterns for $\mathrm{MCC}$ and $\mathrm{CNC}$ obtained after acidic hydrolysis of MCC.

shows a FE-SEM micrograph of agglomerated CNC with their characteristic rod-like shape. The length of CNCs was in the range from 250 to $270 \mathrm{~nm}$ and the average diameter was calculated to be $15-20 \mathrm{~nm}$. $\mathrm{X}$-ray diffraction was used to characterize the structure and polymorphism of the CNC. When cellulose I structure is present, three characteristic peaks can be found in the diffractograms [27]; two shoulder-like peaks around 14 and $16^{\circ}$, and a narrow and more intense peak at around $22^{\circ}$.

Figure 2 presents the X-ray diffraction patterns of starting MCC and derived CNC. The diffraction pattern of MCC shows its characteristic reflections at $12-18,22.7$ and $34.8^{\circ}[14,28,29]$. In CNC diffractogram, samples exhibited a peak around $2 \theta=16.5$ and 22.5 and $34.65^{\circ}$ which are supposed to represent the typical cellulose-I structure.

\subsection{Morphological characterization of PLA nanocomposites.}

GR and CNC nanofillers were used for the preparation of a series of PLA films, as it has been shown in Table 1 . In each case, $1 \mathrm{wt} \%$ of nanofiller was added to PLA by melt mixing. These compounds were hot pressed to produce films. For comparative purposes, PLA film containing the same percentage ( $4 \mathrm{wt} \%$ ) of the organic surfactant Triton X-100 than reinforced films was also prepared.

The obtained films were homogenous with the naked eye. However, as it was expected, the samples containing GR showed a loss of transparency, higher with the increase in the content of GR (Figure 3).

Figure 4 shows the FE-SEM micrographs of the cryogenic fractured surfaces of reference PLA-T and the different PLA-based nanocomposites. PLA-T showed a uniform surface while a more irregular surface was

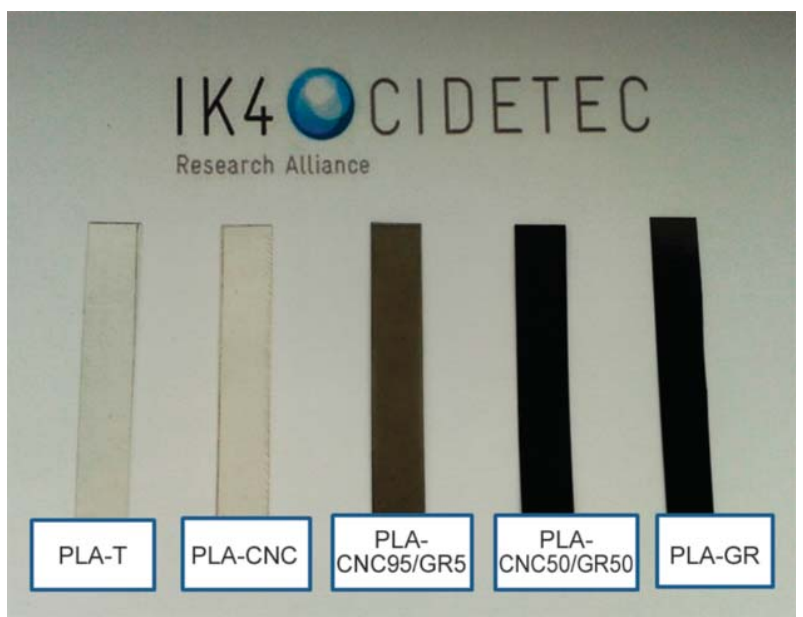

Figure 3. Different formulations of PLA-based films.

found in the PLA nanocomposites. Surfaces corresponding to GR-containing formulations, i.e. PLACNC95/GR5, PLA-CNC50/GR50 and PLA-GR, exhibited higher roughness. The lack of evidence of agglomerates formation may suggest a good dispersion of the nanofillers in the polymeric matrix, which should be verified using a higher resolution. Unfortunately, it was not possible to obtain higher magnification micrographs due to the damage of the samples as consequence of their overheating.

According to literature [30] at low nanofiller content (above $1 \mathrm{wt} \%$ ), plasticizer is able to cover it well, which results in a good distribution on the PLA matrix. The lack of agglomerates together with the high roughness of the surfaces could be regarded as evidence of a strong interaction between the matrix and the nanofillers [31].

\subsection{Mechanical properties of PLA films}

The mechanical properties of the different PLA films were evaluated using tensile tests. The average results for Young's modulus, tensile strength and elongation at break are summarized in Table 2 and the representative stress-strain curves are shown in Figure 5.

In general, values obtained for all the compositions are lower than those reported for pure PLA (e.g, Young's modulus is around $3500 \mathrm{MPa}$ for commercial

Table 2. Mechanical behaviour of PLA-based films.

\begin{tabular}{|l|c|c|c|}
\hline \multicolumn{1}{|c|}{ Sample } & $\begin{array}{c}\boldsymbol{E} \\
{[\mathbf{M P a}]}\end{array}$ & $\begin{array}{c}\boldsymbol{\sigma}_{\mathbf{b}} \\
{[\mathbf{M P a}]}\end{array}$ & $\begin{array}{c}\boldsymbol{\varepsilon}_{\mathbf{b}} \\
{[\mathbf{\%}]}\end{array}$ \\
\hline PLA-T & $2065 \pm 217$ & $46.8 \pm 3.1$ & $3.03 \pm 0.39$ \\
\hline PLA-CNC & $1983 \pm 110$ & $48.1 \pm 3.9$ & $3.20 \pm 0.23$ \\
\hline PLA-CNC95/GR5 & $2144 \pm 113$ & $49.0 \pm 2.3$ & $3.01 \pm 0.11$ \\
\hline PLA-CNC50/GR50 & $2230 \pm 125$ & $52.0 \pm 2.3$ & $3.31 \pm 0.24$ \\
\hline PLA-GR & $1950 \pm 98$ & $49.1 \pm 0.7$ & $3.79 \pm 0.18$ \\
\hline
\end{tabular}




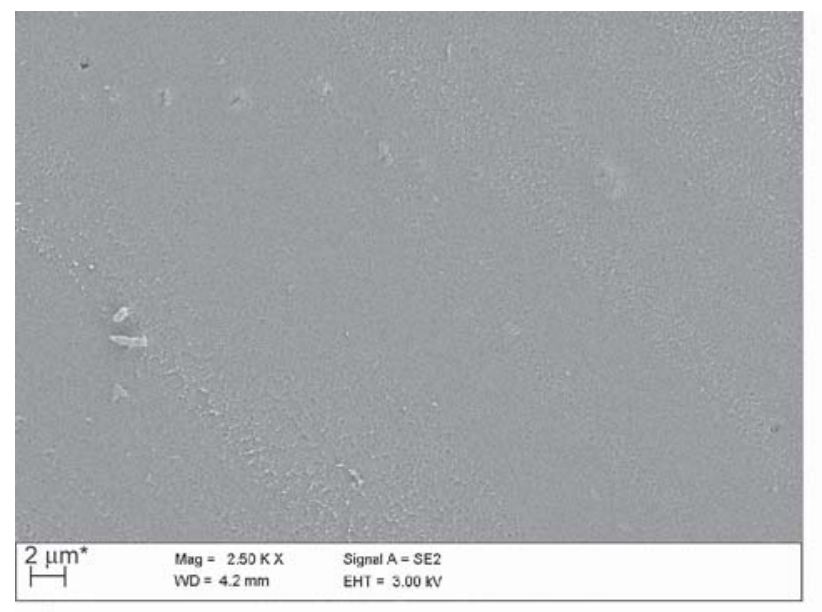

a)

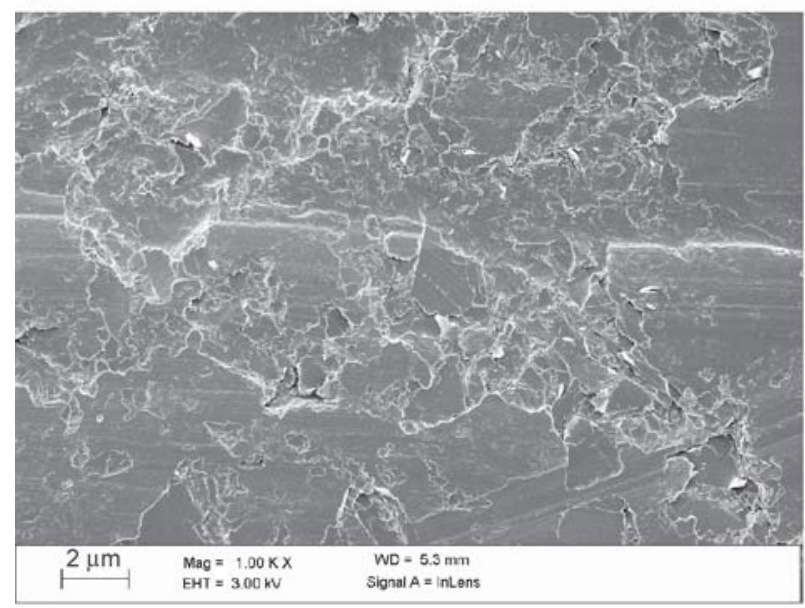

c)

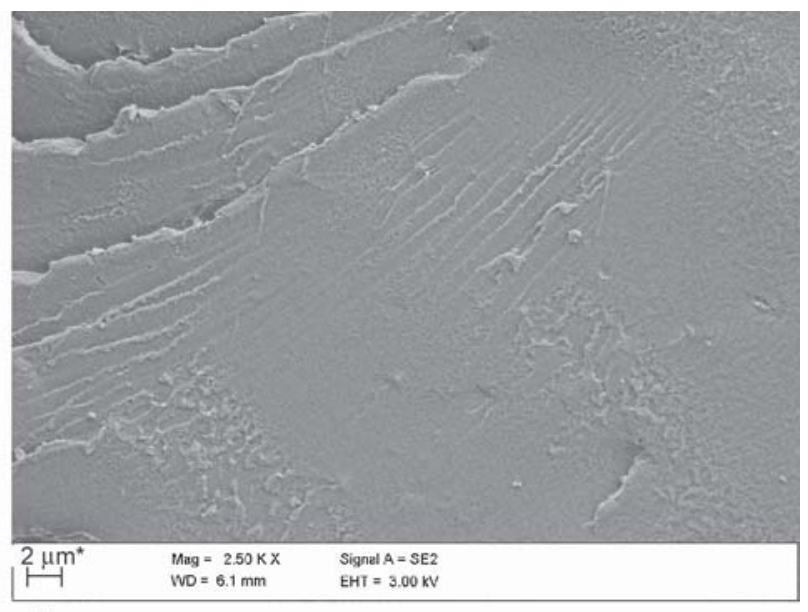

b)

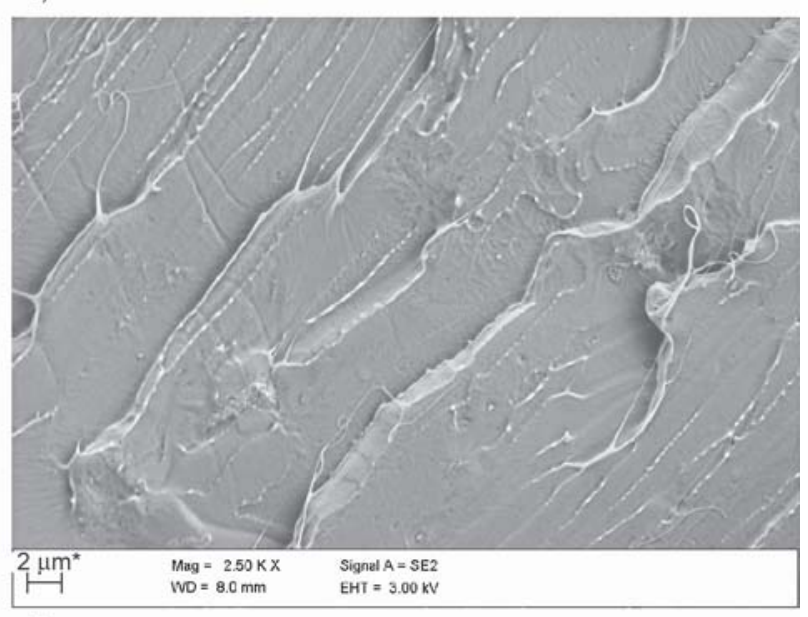

d)

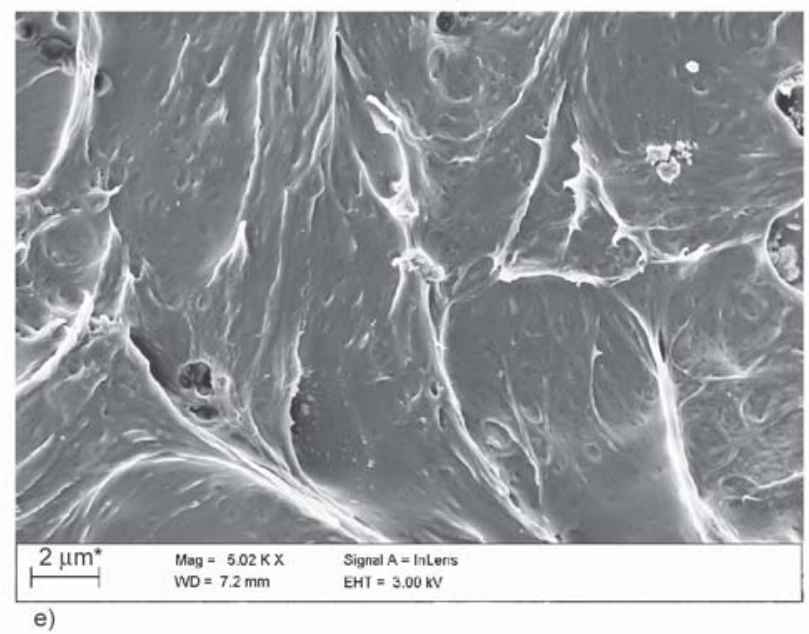

Figure 4. Microstructure of fracture surfaces of (a) PLA-T, (b) PLA-CNC, (c) PLA-CNC95/GR5, (d) PLA-CNC50/GR50 and (e) PLA-GR.

Futerro's PLA), which may be attributed to the plasticizing character of Triton X-100.

All PLA films showed a typical brittle behavior with a similar Young's modulus, slightly higher in the formulations containing $\mathrm{CNC} / \mathrm{GR}$ combination, and especially in the 50/50 ratio in which the Young's modulus was $8 \%$ higher than the reference formulation PLA-T. Similarly, the PLA-CNC50/GR50 showed the highest tensile strength, $11 \%$ higher than the reference, without a significant variation in the elongation at break.

According to the scientific literature, the incorporation of a plasticizer in combination with a nucleating agent affects differently to the mechanical properties depending on their concentration in PLA. On one hand, this combination increases the crystallinity of 
PLA due to the result of two effects: the mobility enhancement of polymer chains allowed by the plasticizer, and the nucleating effect that favors the crystallization rate. Both effects lead to the improvement of the crystallinity which is closely related with the mechanical properties of the polymer [32]. On the other hand, it also has been reported [30] that in CNC reinforced PLA and plasticized with 10 to $20 \mathrm{wt} \%$ of polyethylene glycol (PEG), the mechanical properties were affected by both the reinforcing effect of the $\mathrm{CNC}$ and the plasticizing effect of PEG. Below $6 \mathrm{wt} \%$ of $\mathrm{CNC}$ the tensile strength decreased with the increase in the plasticizer content. However, above $6 \mathrm{wt} \%$ of $\mathrm{CNC}$, the reinforcement effect prevailed over the plasticizing effect. In GR reinforced PLA and a plasticizer content of $10 \mathrm{wt} \%$ the enhancement in the mechanical properties was attributed to the homogeneous dispersion and orientation of the GR nanoplatelets in the polymer matrix and strong interfacial interaction between both components [33]. In the present work, the resulting ternary system PLA/ $\mathrm{CNC} / \mathrm{GR}$ behavior was influenced by the combination of the aforementioned phenomena: the crystallization effect and the reinforcement effect. On one hand, the crystallization was favored by the presence of surfactant and GR. The surfactant could act as a plasticizer allowing certain chain mobility, but the low surfactant content in this case $(4 \mathrm{wt} \%)$ resulted in a moderate elongation at break when compared with higher plasticizer content systems reported in literature (10$20 \mathrm{wt} \%$ ). On the other hand CNC and GR could have both a reinforcing and nucleating effect that resulted in the synergistic enhancement of the mechanical properties. The best results found for the composition PLA-CNC50/GR50 could be attributed to the good dispersion and the strong interaction of both nanofillers in the matrix provided by the surfactant. Higher

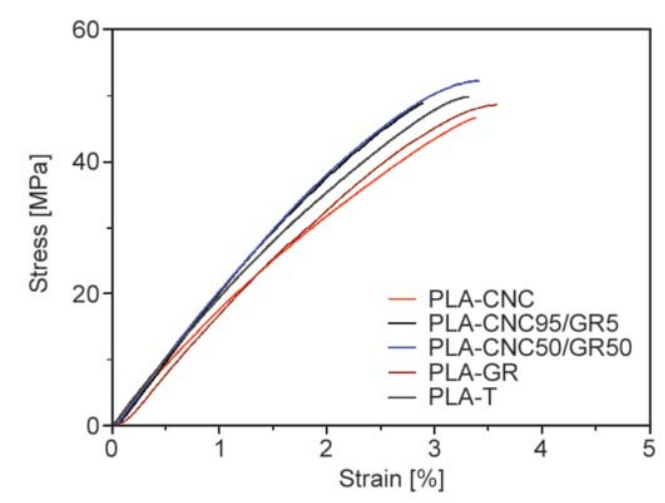

Figure 5. Representative stress-strain curves for PLA-based films. improvements in the mechanical properties could probably be achieved by increasing the total nanofiller content.

\subsection{Thermal characterization}

The thermal stability of the PLA films was assessed by thermogravimetric analysis (TGA). According to literature, pure PLA matrix exhibits, under inert atmosphere, a typical single weight-loss step, with a maximum decomposition rate at around $360^{\circ} \mathrm{C}$. The incorporation of inorganic nanofillers, such as nanoclays, graphene or graphene oxide tends in general to shift the TGA curves towards higher temperatures compared to that of neat PLA [34]. Regarding, CNC, the influence in the thermal degradation of PLA nanocomposites is more difficult to state because it strongly depends on the properties of the filler influenced by the extraction source and hydrolysis conditions $[22,30]$. The obtained TGA curves (Figure 6) showed a significant mass loss ( $>94 \mathrm{wt} \%$ ) between 280 and $380^{\circ} \mathrm{C}$ that corresponds to the breakdown of the polymer backbone.

Table 3 summarizes thermal stability data for PLA films. PLA-T sample degradation started earlier than the nanocomposite films. In particular in those containing CNC, $1 \mathrm{wt} \%$ weight loss occurred between 23 and $52^{\circ} \mathrm{C}$ above the PLA-T degradation temperature $\left(T_{\mathrm{d}}\right)$. These differences became lower as the temperature increased; thus at $5 \mathrm{wt} \%$ weight loss, degradation temperatures of nanocomposites shift by 10 to $20^{\circ} \mathrm{C}$ compared with PLA-T and 9 to $16^{\circ} \mathrm{C}$ at $10 \mathrm{wt} \%$ weight loss. Remarkably, PLA-CNC50/ GR50, the film containing 50/50 of CNC and GR nanofillers, possessed the highest thermal stability, showing that the combination of both nanofillers resulted in the highest improvement of the thermal properties of the film.

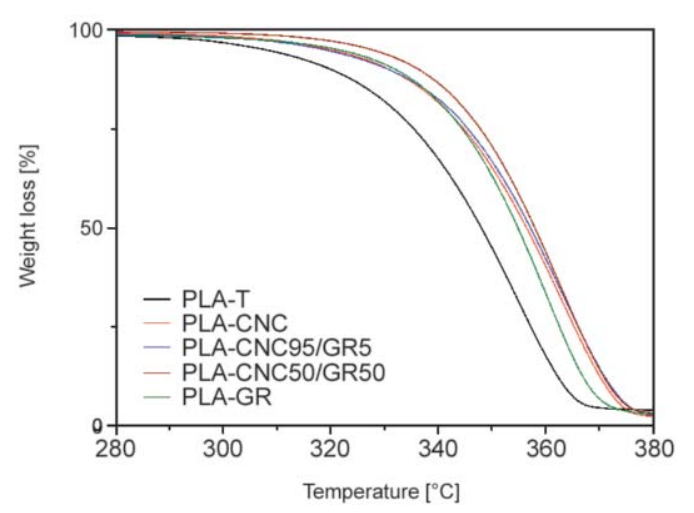

Figure 6. TGA curves for reference PLA-T and PLA-based nanocomposites with $1 \mathrm{wt} \%$ loading. 
Table 3. Thermal stability of PLA-based films.

\begin{tabular}{|c|c|c|c|c|}
\hline Sample & $\begin{array}{c}T_{\mathrm{d} 1 \mathrm{wt} \%} \\
{\left[{ }^{\circ} \mathrm{C}\right]}\end{array}$ & $\begin{array}{c}T_{\mathrm{d} 5 \mathrm{wt} \%} \\
{\left[{ }^{\circ} \mathrm{C}\right]}\end{array}$ & $\begin{array}{c}T_{\mathrm{d} 10 \mathrm{wt} \%} \\
{\left[{ }^{\circ} \mathrm{C}\right]}\end{array}$ & $\begin{array}{c}T_{\mathrm{d} \text { max. }} \\
{\left[{ }^{\circ} \mathrm{C}\right]}\end{array}$ \\
\hline PLA-T & 257 & 308 & 321 & 355 \\
\hline PLA-CNC & 290 & 320 & 330 & 363 \\
\hline PLA-CNC95/GR5 & 280 & 318 & 331 & 363 \\
\hline PLA-CNC50/GR50 & 305 & 328 & 336 & 362 \\
\hline PLA-GR & 262 & 321 & 332 & 360 \\
\hline
\end{tabular}

Table 4. Thermal characterization of PLA and PLA nanocomposites.

\begin{tabular}{|l|c|c|c|c|c|}
\hline \multicolumn{1}{|c|}{ Sample } & $\begin{array}{c}\boldsymbol{T}_{\mathbf{g}} \\
{\left[{ }^{\circ} \mathbf{C}\right]}\end{array}$ & $\begin{array}{c}\boldsymbol{T}_{\mathbf{C C}} \\
{\left[{ }^{\circ} \mathbf{C}\right]}\end{array}$ & $\begin{array}{c}\boldsymbol{T}_{\mathbf{m}} \\
{\left[{ }^{\circ} \mathbf{C}\right]}\end{array}$ & $\begin{array}{c}\Delta \boldsymbol{H}_{\mathbf{m}} \\
{\left[\mathbf{J}^{-\mathbf{1}}\right]}\end{array}$ & $\begin{array}{c}\chi \\
{[\%]}\end{array}$ \\
\hline PLA-T & 51.8 & 94.4 & 175.7 & 21.80 & 24.4 \\
\hline PLA-CNC & 58.2 & 91.3 & 176.4 & 24.63 & 27.9 \\
\hline PLA-CNC95/GR5 & 56.3 & 90.3 & 177.1 & 23.74 & 31.1 \\
\hline PLA-CNC50/GR50 & 53.5 & 96.7 & 178.2 & 20.09 & 28.0 \\
\hline PLA-GR & 55.6 & 87.6 & 177.2 & 37.54 & 34.6 \\
\hline
\end{tabular}

Table 4 summarizes the thermal properties of PLA-T and PLA nanocomposites: glass transition temperature $\left(T_{\mathrm{g}}\right)$, cold crystallization temperature $\left(T_{\mathrm{CC}}\right)$, melting temperature $\left(T_{\mathrm{m}}\right)$, melting enthalpy $\left(\Delta H_{\mathrm{m}}\right)$ and degree of crystallinity $(\chi)$.

It can be observed that $T_{\mathrm{g}}$ values of PLA nanocomposites slightly increased compared to the reference PLA-T. This may be attributed to the chain mobility restriction produced by the addition of nanofillers.

The crystallization, as it was expected, was also influenced by the addition of nanofillers. The $T_{\mathrm{CC}}$ of reference PLA-T was shifted between 3 and $7^{\circ} \mathrm{C}$ to lower temperatures by the incorporation of $\mathrm{CNC}$, GR or CNC combined with GR, indicating a faster crystallization. In the case of CNC50/GR50, the $T_{\mathrm{CC}}$ was shifted towards a higher temperature. In this case, the presence of both nanofillers in the same ratio resulted in a slower crystallization that may be attributed to a more heterogeneous crystallization process. The PLA-T showed a degree of crystallinity of $24.4 \%$ which increased in all the PLA nanocomposites. Remarkably the crystallinity degree was raised up to $31.1 \%$ in the case of PLA-CNC95/5GR and 34.6\% for the PLA-GR system.

The effect of plasticizers and nucleating agents has been already reported, and a broadening of the crystallization temperature window and the crystallization rate is expected from the combination of them [35]. Nucleating agents provide a heterogeneous nucleation at elevated temperatures when the driving force for homogeneous nucleation is weak, while plasticizer improves the crystallization at lower temperatures allowing the chain mobility.

\subsection{Gas barrier properties}

The inherent permeability of polymers to gases and vapours (including water, oxygen, carbon dioxide and organic vapours) is a limiting property for some applications. Regarding PLA, this polymer exhibits medium gas barrier properties and poor water barrier properties [36].

In this work, water vapour and oxygen permeability of PLA-based nanocomposites has been investigated. It is known that oxygen promotes oxidative reactions and the growth of microorganisms in polymeric materials. In addition, absorbed water can modify (increasing or decreasing) the barrier properties of some polymers to oxygen $[37,38]$.

The determined water vapour transmission rate values, measured at $25^{\circ} \mathrm{C}$, are compiled in Table 5 .

The WVTR obtained for PLA-T sample, $6.93 \mathrm{~g} \cdot \mathrm{mm} /\left(\mathrm{m}^{2} \cdot\right.$ day $)$, is a relatively high value compared to reported ones for pure PLA [39, 40], even though superior values could be also found for more amorphous PLA [41]. The plasticizing character of water soluble surfactant Triton could explain the relatively high $W V T R$ value determined for PLA-T film. CNC and GR showed opposite effects on the WVTR of PLA films. The addition of CNC in high ratios with respect to GR increased the WVTR by 7 and $16 \%$ for PLA-CNC and PLA-CNC95/GR5 respectively compared to PLA-T. On the contrary, higher ratios of GR decreased the WVTR. Thus, WVTR was reduced by $4 \%$ in PLA-CNC50/GR50 and 19\% in PLA-GR compared to PLA-T.

The variation of WVTR with the addition of $\mathrm{CNC}$ and GR could be explained on the basis of the different ability of each nanomaterial to interact with water. In this sense, polar groups present on the CNC particles surface would enhance both, the solubility of water and the diffusion process in comparison with

Table 5. Water vapour transmission rate (WVTR) and oxygen permeability coefficient $(P)$ of PLA-T and PLA nanocomposites.

\begin{tabular}{|l|c|c|}
\hline \multicolumn{1}{|c|}{ Sample } & $\begin{array}{c}\boldsymbol{W} \boldsymbol{V T R} \\
{\left[\mathbf{g} \cdot \mathbf{m m} /\left(\mathbf{m}^{\mathbf{2}} \cdot \mathbf{d a y}\right)\right]}\end{array}$ & $\begin{array}{c}\boldsymbol{P} \\
{[\text { Barrer }]}\end{array}$ \\
\hline PLA-T & $6.93 \pm 1.12$ & $0.277 \pm 0.045$ \\
\hline PLA-CNC & $7.40 \pm 0.53$ & $0.236 \pm 0.019$ \\
\hline PLA-CNC95/GR5 & $8.07 \pm 0.29$ & $0.213 \pm 0.010$ \\
\hline PLA-CNC50/GR50 & $6.67 \pm 1.25$ & $0.213 \pm 0.009$ \\
\hline PLA-GR & $5.63 \pm 0.66$ & $0.178 \pm 0.012$ \\
\hline
\end{tabular}


PLA-T sample. In polymers containing hydrophilic fillers, as silicates, it has been observed that clays can reduce the tendency of water to form clusters, as well as the fact that water could be absorbed at specified sites and successive jumps between those sites would generate a quicker diffusion pathway [41, 42]. In relation to GR, a low interaction with water is expected due to its hydrophobic nature. A similar trend in the WVTR was observed in polycarbonate/graphene nanocomposites [43].

From Table 5 results, the obtained permeability coefficient $(P)$ of PLA-T was of 0.276 Barrer. This value is in the range to those reported in literature, 0.14-0.39 Barrer [41, 44-46]. Therefore, for oxygen, the plasticization effect of surfactant Triton apparently does not appreciably affect the permeability coefficient, as opposed to the WVTR case.

In relation to the studied films, an improvement of the barrier character of PLA to oxygen was observed in all the cases being, in general, larger as GR content increased. Thus, for PLA-CNC a reduction of the $P$ of $15 \%$ was observed, $23 \%$ for both PLACNC95/GR5 and PLA-CNC50/GR50 while a reduction of $36 \%$ has been found for PLA-GR. The observed improvement could be ascribed to the tortuosity induced by the nanomaterials addition $[17,47]$. Moreover, the presence of water in the oxygen permeation process could be the reason of the minor reduction of the oxygen permeability coefficient in formulations richer in CNC. This effect was already observed in PLA filled with metallic nanoparticles, in which the results of OTR were different under dry or wet oxygen conditions [41]. In the present work, the larger WVTR values in both PLA-CNC and PLA-CNC95/GR5 formulations could also explain the lower improvement of the barrier character to oxygen of $\mathrm{CNC}$ in wet conditions.
In conclusion, even though there are many factors that would affect permeation, results suggest that interactions of water with nanomaterials at their surfaces play an important role in the permeation of both water and oxygen in wet conditions.

\subsection{Antifungal properties}

Although they are not considered to be major cause of plant disease, Aspergillus species are responsible for several disorders in various plant and plant products [48]. Taking in to account that Aspergillus Niger is well known as a contaminant of fruits, vegetables and food [49], the antifungal activity of PLA-based films was tested against Aspergillus sp., to assess the potential use of $\mathrm{CNC} / \mathrm{GR}$ nanofillers as fungal inhibitors in agricultural films.

Table 6 presents the concentration, fungal inhibition, viability and the mean diameter of the colonies after 7 days incubation as obtained from Cellometer ${ }^{\circledR}$ Mini software and Figure 7 shows digital images after the test.

The first inhibitory value $\left(F G I^{\text {a }}\right)$ represents the comparison with the reference PLA-T (without nanofillers). All the samples presented similar FGI than PLA-T and their inhibition capacity did not significantly change with the addition of the different nanofillers. The fungal growth inhibition relative to live spores in PLA-T $\left(F G I^{\text {b }}\right)$ was also tested showing that PLA-CNC50/GR50 and PLA-GR films presented an antifungal effect of approximately $5 \%$.

The results of viability shown that, in all the cases, the viability of fungal spores decreased with regard to the reference PLA-T (Figure 8). Interestingly, PLA-CNC50/GR50 and PLA-GR formulations decreased the viability of fungal spores in more than $50 \%$; that is to say, even if the microorganism was initially able to grow on the films, less than $50 \%$ of

Table 6. Results of fungal inhibition of PLA films.

\begin{tabular}{|c|c|c|c|c|c|c|}
\hline Sample & $\begin{array}{l}\text { Concentration } \\
{\left[\text { Spores } \cdot \mathrm{mL}^{-1} \text { ] }\right.}\end{array}$ & $\begin{array}{c}\text { Alive spores } \\
{\left[\text { Spores } \cdot \mathbf{m L}^{-1} \text { ] }\right.}\end{array}$ & $\begin{array}{c}\text { Diameter } \\
{[\mu \mathrm{m}]}\end{array}$ & $\begin{array}{c}F G I^{\mathrm{a}} \\
{[\%]}\end{array}$ & $\begin{array}{c}F G I^{b} \\
{[\%]}\end{array}$ & $\begin{array}{c}\text { Viability }^{\mathrm{c}} \\
{[\%]}\end{array}$ \\
\hline Control & $1.24 \cdot 10^{7}(0.61)$ & $1.16 \cdot 10^{7}(0.35)$ & $4.50(3.95)$ & - & - & 93.55 \\
\hline PLA-T & $5.28 \cdot 10^{5}(0.83)$ & $4.26 \cdot 10^{5}(0.47)$ & $3.20(0.01)$ & - & - & 80.76 \\
\hline PLA-CNC & $15.9 \cdot 10^{5}(0.56)$ & $9.80 \cdot 10^{5}(0.12)$ & $3.17(0.46)$ & $\mathrm{NFI}^{*}$ & $\mathrm{NFI}^{*}$ & 61.38 \\
\hline PLA-CNC95/GR5 & $8.46 \cdot 10^{5}(0.04)$ & $5.20 \cdot 10^{5}(0.06)$ & $4.05(0.78)$ & $\mathrm{NFI}^{*}$ & $\mathrm{NFI}^{*}$ & 61.47 \\
\hline PLA-CNC50/GR50 & $8.44 \cdot 10^{5}(0.05)$ & $4.04 \cdot 10^{5}(0.03)$ & $3.85(0.49)$ & $\mathrm{NFI}^{*}$ & 5.16 & 47.86 \\
\hline PLA-GR & $9.83 \cdot 10^{5}(0.12)$ & $4.01 \cdot 10^{5}(0.09)$ & $3.30(0.28)$ & $\mathrm{NFI}^{*}$ & 5.87 & 40.79 \\
\hline
\end{tabular}

${ }^{a}$ Fungal growth inhibition relative to control with PLA-T.

${ }^{b}$ Fungal growth inhibition relative to live spores in control with PLA-T.

cLive spores/total spores.

*NFI: No fungal inhibition.

Values in parenthesis represent \% RSD. 


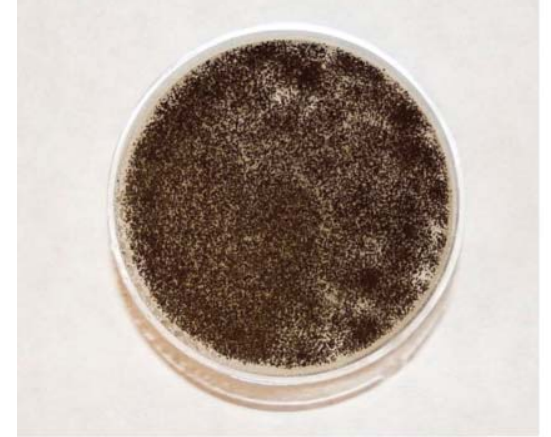

a)

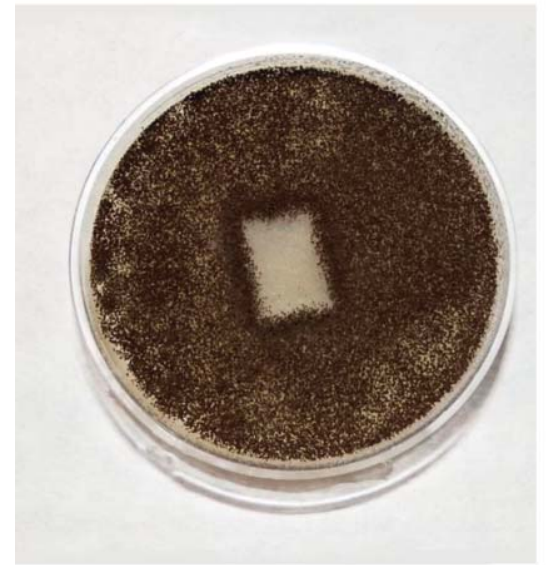

d)

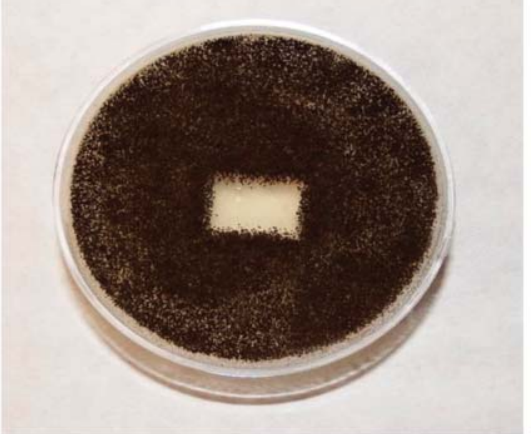

b)

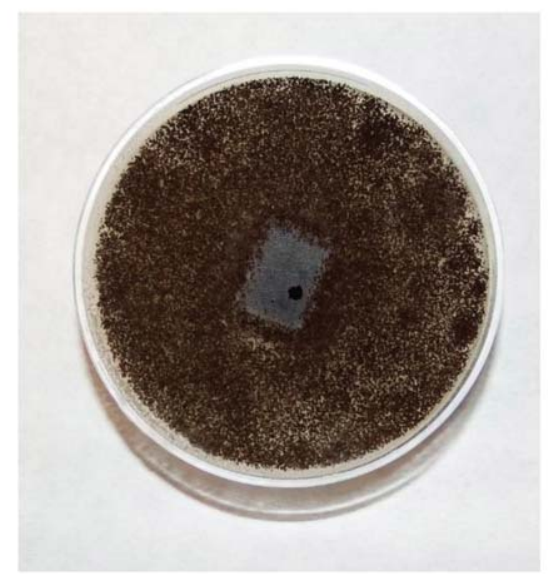

e)

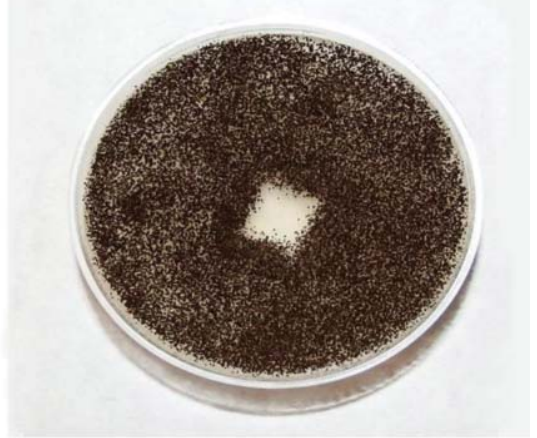

c)

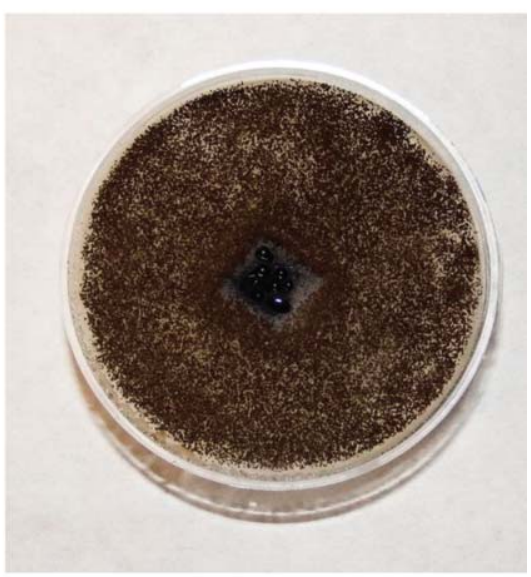

f)

Figure 7. Images of control sample and PLA-based films after Aspergillus sp. incubation. a) Control, b) PLA-T, c) PLACNC, d) PLA-CNC95/GR5, e) PLA-CNC50/GR50 and f) PLA-GR.

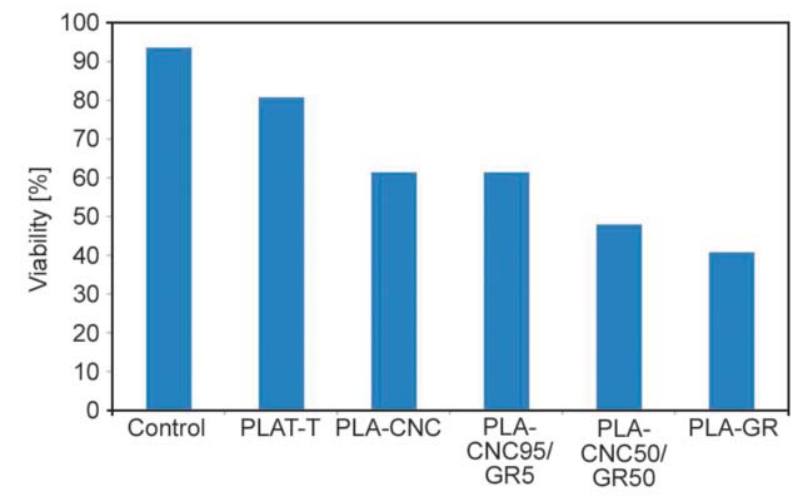

Figure 8. Viability of fungal spores for PLA based films.

spores survived. This phenomenon might be attributed to the antifungal effect of graphene [50]. It was observed that for PLA-CNC50/GR50 and PLA-GR formulations the antifungal activity increased with the graphene content, higher for PLA-GR formulation.

\section{Conclusions}

CNC synthesized by acidic hydrolysis and GR nanoplatelets were combined for the preparation of PLAbased nanocomposites. Both nanomaterials were incorporated in two different ratios into PLA by melt blending technique, a conventional method for plastic compounding both at laboratory and industrial scale. The obtained nanocomposites were further processed for the manufacturing of films by hot pressing. The morphological characterization by FE-SEM showed an apparently good dispersion of nanofiller in PLA. Assessment of the mechanical properties of films revealed an enhancement of the tensile strength and the Young's modulus for PLA-CNC95/GR5 and PLA-CNC50/GR50 formulations. Similarly, PLACNC50/GR50 film exhibited the highest thermal stability. DSC analysis showed a slightly increase in $T_{\mathrm{g}}$ values of all PLA nanocomposites compared to the reference PLA-T which could be attributed to the chain mobility restriction produced by the addition of nanofillers. The $T_{\mathrm{CC}}$ was shifted towards lower temperatures by the incorporation of nanofillers indicating a faster crystallization process, with the exception of PLA-CNC50/GR50. In that case the slower crystallization could be attributed to a more heterogeneous crystallization process.

Regarding gas barrier properties, even though the variation of the measurements of WVTR and OTR in wet conditions were slight for the investigated films, an improvement in the OTR was observed for 
PLA-CNC95/GR5, PLA-CNC50/GR50 and PLAGR, i.e. films containing GR, suggesting that interactions of water with both nanomaterials played an important role in the studied gas barrier properties. Finally, the antifungal properties assessment revealed a significant improvement in the antifungal activity of PLA-CNC50/GR50 and PLA-GR, attributed to the antifungal effect of GR.

Thus, the incorporation of CNC and GR in PLA showed a favourable impact in the overall properties of the obtained films due to the combination of both nanomaterials with only $1 \mathrm{wt} \%$ of nanofillers. Further improvements could probably be achieved by increasing the loading level of CNC-GR in the nanocomposite, at the expense of a high loss of transparency of resulting materials. Additionally, in applications in which transparency is not an essential requirement high GR/CNC ratio could also be investigated.

\section{Acknowledgements}

Financial support from the European Commission (FP7 Program, ECLIPSE project FP7-NMP-280786) and Basque Country Government (IT-618-13) are gratefully acknowledged.

\section{References}

[1] Reddy M. M., Vivekanandhan S., Misra M., Bhatia S. K., Mohanty A. K.: Biobased plastics and bionanocomposites: Current status and future opportunities. Progress in Polymer Science, 38, 1653-1689 (2013).

https://doi.org/10.1016/j.progpolymsci.2013.05.006

[2] Razza F., Degli Innocenti F.: Bioplastics from renewable resources: The benefits of biodegradability. Asia-Pacific Journal of Chemical Engineering, 7, 301-309 (2012). https://doi.org/10.1002/apj.1648

[3] Mitra B. C.: Environment friendly composite materials: Biocomposites and green composites. Defence Science Journal, 64, 244-261 (2014). https://doi.org/10.14429/dsj.64.7323

[4] Garlotta D.: A literature review of poly(lactic acid). Journal of Polymers and the Environment, 9, 63-84 (2001). https://doi.org/10.1023/A:1020200822435

[5] Shen L., Worrell E., Patel M.: Present and future development in plastics from biomass. Biofuels, Bioproducts and Biorefining, 4, 25-40 (2010).

https://doi.org/10.1002/bbb.189

[6] Alsaheb R. A. A., Aladdin A., Othman N. Z., Malek R. A., Leng O. M., Aziz R., El Enshasy H. A.: Recent applications of polylactic acid in pharmaceutical and medical industries. Journal of Chemical and Pharmaceutical Research, 7, 51-63 (2015).
[7] Smith A., Hunneyball I. M.: Evaluation of poly(lactic acid) as a biodegradable drug delivery system for parenteral administration. International Journal of Pharmaceutics, 30, 215-220 (1986).

https://doi.org/10.1016/0378-5173(86)90081-5

[8] Lasprilla A. J., Martinez G. A., Lunelli B. H., Jardini A. L., Filho R. M.: Poly-lactic acid synthesis for application in biomedical devices - A review. Biotechnology Advances, 30, 321-328 (2012).

https://doi.org/10.1016/j.biotechadv.2011.06.019

[9] Li J., Xiao P., Li H., Zhang Y., Xue F., Luo B., Huang S., Shang Y., Wen H., de Chaville Christiansen J., Yu D., Jiang S.: Crystalline structures and crystallization behaviors of poly(L-lactide) in poly(L-lactide)/graphene nanosheet composites. Polymer Chemistry, 6, 39884002 (2015).

https://doi.org/10.1039/c5py00254k

[10] Armentano I., Bitinis N., Fortunati E., Mattioli S., Rescignano N., Verdejo R., Lopez-Manchado M. A., Kenny J. M.: Multifunctional nanostructured PLA materials for packaging and tissue engineering. Progress in Polymer Science, 38, 1720-1747 (2013).

https://doi.org/10.1016/j.progpolymsci.2013.05.010

[11] Fenni S. E., Monticelli O., Conzatti L., Doufnoune R., Stagnaro P., Haddaoui N., Cavallo D.: Correlating the morphology of poly(L-lactide)/poly(butylene succinate)/ graphene oxide blends nanocomposites with their crystallization behavior. Express Polymer Letters, 12, 58-70 (2018).

https://doi.org/10.3144/expresspolymlett.2018.5

[12] Darder M., Aranda P., Ruiz-Hitzky E.: Bionanocomposites: A new concept of ecological, bioinspired, and functional hybrid materials. Advanced Materials, 19, 1309-1319 (2007). https://doi.org/10.1002/adma.200602328

[13] Peponi L., Puglia D., Torre L., Valentini L., Kenny J. M.: Processing of nanostructured polymers and advanced polymeric based nanocomposites. Materials Science and Engineering R: Reports, 85, 1-46 (2014). https://doi.org/10.1016/j.mser.2014.08.002

[14] Johar N., Ahmad I., Dufresne A.: Extraction, preparation and characterization of cellulose fibres and nanocrystals from rice husk. Industrial Crops and Products, 37, 93-99 (2012). https://doi.org/10.1016/j.indcrop.2011.12.016

[15] Mathew A. P., Oksman K., Sain M.: The effect of morphology and chemical characteristics of cellulose reinforcements on the crystallinity of polylactic acid. Journal of Applied Polymer Science, 101, 300-310 (2006). https://doi.org/10.1002/app.23346

[16] Uddin A. J., Araki J., Gotoh Y.: Toward 'strong' green nanocomposites: Polyvinyl alcohol reinforced with extremely oriented cellulose whiskers. Biomacromolecules, 12, 617-624 (2011). https://doi.org/10.1021/bm101280f 
[17] Pinto A. M., Cabral J., Pacheco Tanaka D. A., Mendes A. M., Magalhães F. D.: Effect of incorporation of graphene oxide and graphene nanoplatelets on mechanical and gas permeability properties of poly(lactic acid) films. Polymer International, 62, 33-40 (2013).

https://doi.org/10.1002/pi.4290

[18] Pinto A. M., Moreira S., Gonçalves I., Gama F. M., Mendes A. M., Magalhães F. D.: Biocompatibility of poly(lactic acid) with incorporated graphene-based materials. Colloids and Surfaces B: Biointerfaces, 104, 229-238 (2013).

https://doi.org/10.1016/j.colsurfb.2012.12.006

[19] Tong X-Z., Song F., Li M-Q., Wang X-L., Chin I-J., Wang Y-Z.: Fabrication of graphene/polylactide nanocomposites with improved properties. Composites Science and Technology, 88, 33-38 (2013). https://doi.org/10.1016/j.compscitech.2013.08.028

[20] Mittal V., Chaudhry A., Luckachan G. E.: Biopolymer - Thermally reduced graphene nanocomposites: Structural characterization and properties. Materials Chemistry and Physics, 147, 319-332 (2014). https://doi.org/10.1016/j.matchemphys.2014.05.007

[21] Fortunati E., Armentano I., Zhou Q., Puglia D., Terenzi A., Berglund L. A., Kenny J. M.: Microstructure and nonisothermal cold crystallization of PLA composites based on silver nanoparticles and nanocrystalline cellulose. Polymer Degradation and Stability, 97, 2027 2036 (2012).

https://doi.org/10.1016/j.polymdegradstab.2012.03.027

[22] Fortunati E., Armentano I., Zhou Q., Iannoni A., Saino E., Visai L., Berglund L. A., Kenny J. M.: Multifunctional bionanocomposite films of poly(lactic acid), cellulose nanocrystals and silver nanoparticles. Carbohydrate Polymers, 87, 1596-1605 (2012).

https://doi.org/10.1016/j.carbpol.2011.09.066

[23] Fortunati E., Peltzer M., Armentano I., Jiménez A., Kenny J. M.: Combined effects of cellulose nanocrystals and silver nanoparticles on the barrier and migration properties of PLA nano-biocomposites. Journal of Food Engineering, 118, 117-124 (2013).

https://doi.org/10.1016/j.jfoodeng.2013.03.025

[24] Fukushima K., Murariu M., Camino G., Dubois P.: Effect of expanded graphite/layered-silicate clay on thermal, mechanical and fire retardant properties of poly (lactic acid). Polymer Degradation and Stability, 95, 1063-1076 (2010).

https://doi.org/10.1016/j.polymdegradstab.2010.02.029

[25] Montes S., Carrasco P. M., Ruiz V., Cabañero G., Grande H. J., Labidi J., Odriozola I.: Synergistic reinforcement of poly(vinyl alcohol) nanocomposites with cellulose nanocrystal-stabilized graphene. Composites Science and Technology, 117, 26-31 (2015).

https://doi.org/10.1016/j.compscitech.2015.05.018

[26] Turner J. F., Riga A., O'Connor A., Zhang J., Collis J.: Characterization of drawn and undrawn poly-L-lactide films by differential scanning calorimetry. Journal of Thermal Analysis and Calorimetry, 75, 257-268 (2004). https://doi.org/10.1023/B:JTAN.0000017347.08469.b1
[27] Herrera M. A., Mathew A. P., Oksman K.: Characterization of cellulose nanowhiskers: A comparison of two industrial bio-residues in ' 6 th $E$ EIGM International Conference on Advanced Materials Research' Nancy, France, Vol 31, 012006/1-012006/8 (2012). https://doi.org/10.1088/1757-899X/31/1/012006

[28] De S. Costa L. A., Fonsêca A. F., Pereira F. V., Druzian J. I.: Extraction and characterization of cellulose nanocrystals from corn stover. Cellulose Chemistry and Technology, 49, 127-133 (2015).

[29] Möller M., Harnisch F., Schröder U.: Hydrothermal liquefaction of cellulose in subcritical water - the role of crystallinity on the cellulose reactivity. RSC Advances, 3, 11035-11044 (2013). https://doi.org/10.1039/C3RA41582A

[30] Zhang P., Gao D., Zou P., Wang J. B.: Preparation and thermomechanical properties of nanocrystalline cellulose reinforced poly(lactic acid) nanocomposites. Journal of Applied Polymer Science, 134, 44683-44692 (2017). https://doi.org/10.1002/APP.44683

[31] Keramati M., Ghasemi I., Karrabi M., Azizi H., Sabzi M.: Dispersion of graphene nanoplatelets in polylactic acid with the aid of a zwitterionic surfactant: Evaluation of the shape memory behavior. Polymer-Plastics Technology and Engineering, 55, 1039-1047 (2016). https://doi.org/10.1080/03602559.2015.1132458

[32] Fehri S., Cinelli P., Coltelli M. B., Anguillesi I., Lazzeri A.: Thermal properties of plasticized poly (lactic acid) (PLA) containing nucleating agent. International Journal of Chemical Engineering and Applications, 7, 8588 (2016). https://doi.org/10.7763/IJCEA.2016.V7.548

[33] Chieng B. W., Ibrahim N. A., Yunus W. M. Z., Hussein M. Z.: Poly(lactic acid)/poly(ethylene glycol) polymer nanocomposites: Effects of graphene nanoplatelets. Polymers, 6, 93-04 (2014). https://doi.org/10.3390/polym6010093

[34] Raquez J-M., Habibi Y., Murariu M., Dubois P.: Polylactide (PLA)-based nanocomposites. Progress in Polymer Science, 38, 1504-1542 (2013).

https://doi.org/10.1016/j.progpolymsci.2013.05.014

[35] Saeidlou S., Huneault M. A., Li H., Park C. B.: Poly(lactic acid) crystallization. Progress in Polymer Science, 37, 1657-1677 (2012). https://doi.org/10.1016/j.progpolymsci.2012.07.005

[36] Delpouve N., Stoclet G., Saiter A., Dargent E., Marai S.: Water barrier properties in biaxially drawn poly(lactic acid) films. The Journal of Physical Chemistry B, 116, 4615-4625 (2012). https://doi.org/10.1021/jp211670g

[37] Krizan T. D., Coburn J. C., Blatz P. S.: Structure of amorphous polyamides. Effect on oxygen permeation properties. in 'Barrier polymers and structures' (ed.: Koros W. J.) ACS Symposium Series, American Chemical Society, Washington, 111-125 (1990). https://doi.org/10.1021/bk-1990-0423.ch005 
[38] Chern R. T., Koros W. J., Sanders E. S., Yui R. J.: 'Second component' effects in sorption and permeation of gases in glassy polymers. Journal of Membrane Science, 15, 157-169 (1983).

https://doi.org/10.1016/S0376-7388(00)80395-6

[39] Courgneau C., Domenek S., Guinault A., Avérous L., Ducruet V.: Analysis of the structure-properties relationships of different multiphase systems based on plasticized poly(lactic acid). Journal of Polymers and the Environment, 19, 362-371 (2011).

https://doi.org/10.1007/s10924-011-0285-5

[40] Duan Z., Thomas N. L., Huang W.: Water vapour permeability of poly(lactic acid) nanocomposites. Journal of Membrane Science, 445, 112-118 (2013). https://doi.org/10.1016/j.memsci.2013.06.008

[41] Lizundia E., Vilas J. L., Sangroniz A., Etxeberria A.: Light and gas barrier properties of PLLA/metallic nanoparticles composite films. European Polymer Journal, 91, 10-20 (2017). https://doi.org/10.1016/j.eurpolymj.2017.03.043

[42] Garcia A., Eceolaza S., Iriarte M., Uriarte C., Etxeberria A.: Barrier character improvement of an amorphous polyamide (Trogamid) by the addition of a nanoclay. Journal of Membrane Science, 301, 190-199 (2007). https://doi.org/10.1016/j.memsci.2007.06.018

[43] Oyarzabal A., Cristiano-Tassi A., Laredo E., Newman D., Bello A., Etxeberría A., Eguiazabal J. I., Zubitur M., Mugica A., Müller A. J.: Dielectric, mechanical and transport properties of bisphenol A polycarbonate/graphene nanocomposites prepared by melt blending. Journal of Applied Polymer Science, 134, 44654-44667 (2017). https://doi.org/10.1002/app.44654

[44] Bao L., Dorgan J. R., Knauss D., Hait S., Oliveira N. S., Maruccho I. M.: Gas permeation properties of poly (lactic acid) revisited. Journal of Membrane Science, 285, 166-172 (2006).

https://doi.org/10.1016/j.memsci.2006.08.021
[45] Gonçalves C. M. B., Tomé L. C., García H., Brandão L., Mendes A. M., Marrucho I. M.: Effect of natural and synthetic antioxidants incorporation on the gas permeation properties of poly(lactic acid) films. Journal of Food Engineering, 116, 562-571 (2013).

https://doi.org/10.1016/j.jfoodeng.2012.12.034

[46] Sangroniz A., Chaos A., Garcia Y. M., Fernández J., Iriarte M., Etxeberria A.: Improving the barrier character of polylactide/phenoxy immiscible blend using poly(lactide-co- $\varepsilon$-caprolactone) block copolymer as a compatibilizer. Journal of Applied Polymer Science, 134, 45396/1-45396/10 (2017).

https://doi.org/10.1002/app.45396

[47] Choudalakis G., Gotsis A. D.: Permeability of polymer/clay nanocomposites: A review. European Polymer Journal, 45, 967-984 (2009). https://doi.org/10.1016/j.eurpolymj.2009.01.027

[48] Perrone G., Susca A., Cozzi G., Ehrlich K., Varga J., Frisvad J. C., Meijer M., Noonim P., Mahakarnchanakul W., Samson R. A.: Biodiversity of Aspergillus species in some important agricultural products. Studies in Mycology, 59, 53-66 (2007). https://doi.org/10.3114/sim.2007.59.07

[49] Yahyaoui M., Gordobil O., Díaz R. H., Abderrabba M., Labidi J.: Development of novel antimicrobial films based on poly(lactic acid) and essential oils. Reactive and Functional Polymers, 109, 1-8 (2016) https://doi.org/10.1016/j.reactfunctpolym.2016.09.001

[50] Sawangphruk M., Srimuk P., Chiochan P., Sangsri T., Siwayaprahm P.: Synthesis and antifungal activity of reduced graphene oxide nanosheets. Carbon, 50, 51565161 (2012).

https://doi.org/10.1016/j.carbon.2012.06.056 